Original article

\title{
Adoption of a non-invasive prenatal test (NIPT) in prenatal screening in Moscow: first results
}

\author{
Anton S. Olenev ${ }^{1}$, Elena E. Baranova ${ }^{2}$, Olesya V. Sagaydak ${ }^{2}$, Alexandra M. Galaktionova ${ }^{2}$, \\ Ekaterina S. Kuznetsova ${ }^{2}$, Madina T. Kaplanova ${ }^{2}$, Maxim S. Belenikin ${ }^{2}$, Ekaterina N. Songolova ${ }^{3}$ \\ ${ }^{1}$ City clinical hospital №24, Moscow, Russia \\ ${ }^{2}$ LLC "Evogen", Moscow, Russia \\ ${ }^{3}$ City clinical hospital №27 n.a. L.A. Vorokhobova, Moscow, Russia
}

Received 20 November 2020, Revised 12 January 2021, Accepted 20 February 2021

(C) 2020, Olenev A.S., Baranova E.E., Sagaydak O.V., Galaktionova A.M., Kuznetsova E.S., Kaplanova M.T., Belenikin M.S., Songolova E.N.

(C) 2020, Russian Open Medical Journal

Abstract: The objective - To assess the effectiveness of including NIPT in the structure of prenatal diagnostics in Moscow.

Material and Methods - Totally 5,181 pregnancies undergoing screening for fetal trisomy using NIPT during the period from 01.04 .2020 to 30.09.2020 in Russia. According to the results of biochemical blood test, the patients were divided into two groups: group of high risk (cutoff $\geq 1: 100$ ) ( $n=208$ ) and group of intermediate risk (cut-off 1:101 - 1:2500) ( $n=4,973)$. Patients at high-risk cell-free DNA (cfDNA) were offered an invasive procedure, followed by genetic analysis (cytogenetic or molecular karyotyping).

Results - Among the analysed samples, 117 (2.3\%) had a high risk of the following common fetal chromosome abnormalities by NIPT: trisomy 21 in 50 cases, trisomy 18 in 17 cases, trisomy 13 in 5 cases, and sex chromosome aneuploidy (SCA) in 22 cases. Additionally, rare autosomal trisomies and/or subchromosomal arrangements were revealed in 23 cases. We found associations between cfDNA concentration and high risk of aneuploidies (particularly trisomy 21) and fetal sex and between low fetal fraction (FF) and body mass index (BMI) as well as maternal weight. Additionally, a high risk of trisomy 21 was associated with the term gestation.

Conclusion - The effectiveness of technological resources that are based on cfDNA testing for detecting abnormal fetal chromosome numbers and other chromosomal anomalies is high and reduce rates of false positive results. Therefore, NIPT should be more widely used as a first-line screening method.

Keywords: cfDNA, non-invasive prenatal testing, NIPT, NIPS, genome-wide, maternal serum, screening, prenatal screening, fetal aneuploidies, amniocentesis, trisomy 21 , trisomy 18 , trisomy 13 , common trisomies, rare autosomal trisomies, implementation study.

Cite as Olenev AS, Baranova EE, Sagaidak OV, Galaktionova AM, Kuznetsova ES, Kaplanova MT, Belenikin MS, Songolova EN. Adoption of a non-invasive prenatal test (NIPT) in prenatal screening in Moscow: first results. Russian Open Medical Journal 2021; 10 : e0110.

Correspondence to Olesya V. Sagaydak, Email: sagaydak@evogenlab.ru.

\section{Introduction}

Great efforts are taken worldwide to lower infant mortality. In Russia along with developing of medicine technologies and maternal age rising, infant deaths due to chromosomal anomalies and congenital diseases reaches up to $20-23 \%$ in the infant mortality structure [1].

One of the key instruments for infant and perinatal death rate lowering is prenatal screening, aimed on detecting and assessing of fetal chromosomal abnormalities.

Traditional prenatal screening includes ultrasound examinations and maternal blood tests for biochemical markers. More recently, a new screening method called noninvasive prenatal testing (NIPT) has been introduced. NIPT is analyzing maternal blood cell-free DNA (cfDNA) derived from placenta and fetus. To align and count DNA fragments floating in the pregnant women plasma massive parallel sequencing is used. NIPT shows high accuracy for most common trisomies: 21,18 , and 13 , though is also used to detect sex chromosome's abnormalities and others.
Over the past 2 years, NIPT has become integrated into prenatal care of several countries, including Netherlands, Belgium [2-5].

Originally American College of Obstetricians and Gynecologists (ACOG) suggested the use of NIPT in women with high risk evaluated by traditional screening, but to date it has been shown that sensitivity and specificity of the test among all of women is similar to that in the high risk [6]. Current international guidelines suggest the use of NIPT during pregnancy, regardless of the initial risk $[6,7]$.

Fast NIPT adoption to the clinical practice reflects its benefits. It is a non-invasive, relatively painless, and safe procedure with no risk of miscarriage which is usually associated with other prenatal procedures, as amniocentesis and chorionic villus sampling (CVS). NIPT has a higher sensitivity and specificity and more effective overall in detecting common aneuploidies (up to 99\%), when compared with traditional prenatal screening, that is not more than $96 \%$ in countries with well-organized health systems, but usually stays about $85-90 \%[8,9]$. 


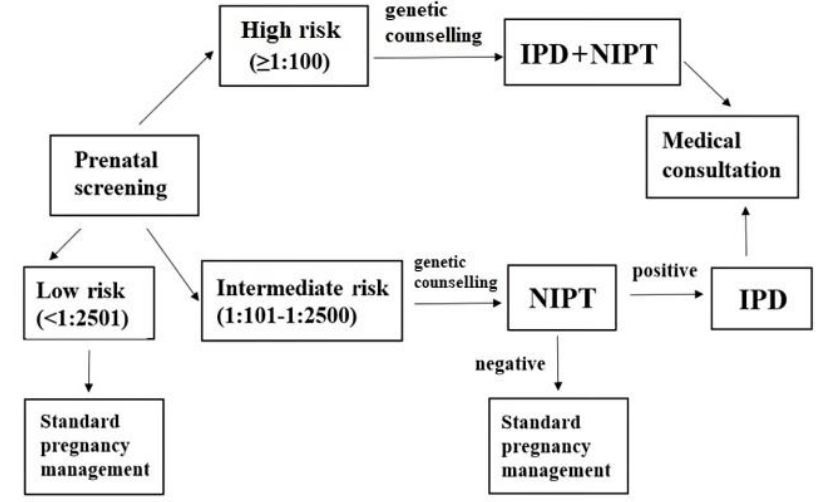

Figure 1. An illustration of the sequence of actions of pregnant women during their first trimester, taking into account the local regulation.

*IPD is obligatory for high-risk group of pregnant women and is optional for intermediate-risk group. NIPT, non-invasive prenatal testing; IPD, invasive prenatal diagnostics.

Table 1. Maternal and pregnancy characteristics

\begin{tabular}{lc}
\hline Characteristics & Number of cases (\%) \\
\hline Maternal age (years) & \\
$<20$ & $37(0.7 \%)$ \\
$20-24$ & $203(3.9 \%)$ \\
$25-29$ & $684(13.2 \%)$ \\
$30-34$ & $1511(29.2 \%)$ \\
$35-39$ & $1915(37.0 \%)$ \\
$\geq 40$ & $831(16.0 \%)$ \\
\hline Body mass index (BMI, kg/m ${ }^{2}$ ) & \\
$<18.5$ & $260(5.0 \%)$ \\
$18.5-24.9$ & $3015(58.2 \%)$ \\
$25-30$ & $1200(23.2 \%)$ \\
$>30$ & $706(13.6 \%)$ \\
\hline Gestational age at sampling & \\
$11-13^{+6}$ weeks & $2728(52.7 \%)$ \\
$14-15^{+6}$ weeks & $2051(39.5 \%)$ \\
$16-20^{+6}$ weeks & $387(7.5 \%)$ \\
$\geq 21$ weeks & $15(0.3 \%)$ \\
\hline Type of pregnancy & \\
Singleton & $5106(98.6 \%)$ \\
Twin & $64(1.2 \%)$ \\
Vanishing twin & $11(0.2 \%)$ \\
\hline Mode of conception & \\
Spontaneous & $5016(96.8 \%)$ \\
Artificial reproductive technology & $165(3.2 \%)$ \\
\hline Maternal serum screening & $208(4.0 \%)$ \\
High risk ( $\geq 1: 100)$ & $4973(96.0 \%)$ \\
Intermediate risk (1:101 - 1:2500) &
\end{tabular}

Though being very technological and accurate in less than 3\% of tests false-positive and false-negative results may occur. Biological reasons such as maternal malignancy, fetoplacental mosaicism, or non-identical vanishing twins may contribute to incorrect predictions of the fetal condition [10]. However, in spite of these limitations, NIPT is believed to be more accurate than traditional prenatal screening with much less percentage of falsepositive results being as low as $0.08 \%$ [11].

In Russia, currently, prenatal screening of the first trimester includes ultrasound examination at 11-14 weeks of gestation with the determination of maternal blood serum markers. Based on the results a complex software calculation of chromosomal pathology individual risk is performed [12]. Using indirect characteristics makes traditional prenatal screening insufficiently sensitive and specific, that leads to false-positive and false-negative results and thus unfounded invasive interventions, as well as undiagnosed cases of fetal chromosomal pathology.

The development of molecular technologies all over the world demanded to revise the existing system of prenatal examination of pregnant women in Russia.

Until recently, in Russia, NIPT was primarily a commercial additional test. Since March 13, 2020 NIPT has been included in the structure of prenatal screening in Moscow as part of a pilot project [13]. Since that work on national standards and clinical guidelines for NIPT is ongoing.

The aim of the present study was to assess the effectiveness of including NIPT in the structure of prenatal diagnostics in Moscow.

\section{Material and Methods}

\section{Recruitment criteria}

Based on the local regulation [13] pregnant women at high-risk of fetus chromosomal anomalies (cut-off $\geq 1: 100$ ) according to the analysis of biochemical markers in the maternal blood and ultrasound examinations should undergo a genetic counseling, an invasive prenatal diagnostic (IPD) and a blood sampling for NIPT. Blood test for NIPT is performed in the same day of the IPD (Figure 1)

Pregnant women at group of risk 1:101-1:2500 are offered to perform NIPT optionally. When receiving a positive (high-risk) NIPT result $(>1: 100)$, pregnant women should also undergo a genetic consulting.

\section{Sample collection, sequencing and aneuploidies classification}

Between April and September 2020, total of 5,181 pregnant women blood samples were analyzed.

Blood is drawn in one $10 \mathrm{~mL}$ Cell-Free DNA BCT CE tube (Streck) and shipped at room temperature by courier in specific transport containers. Time between blood collection and plasma isolation was up to four days. Blood plasma was prepared by twostep centrifugation standard procedure protocol. Firstly, whole blood sample was centrifuged at $1.600 \mathrm{~g}$ for $15 \mathrm{~min}$ at $4^{\circ} \mathrm{C}$. The supernatant was transferred to sterile $2.0 \mathrm{ml}$ Eppendorf (EP) tubes. Second centrifugation was performed at $16.000 \mathrm{~g}$ for 10 $\min$ at $4^{\circ} \mathrm{C}$. The final supernatant was transferred to new EP tubes. Tubes were stored temporarily (up to one week) at $-20^{\circ} \mathrm{C}$ before further processing or stored at $-80^{\circ} \mathrm{C}$ for long keeping. After that cell-free DNA isolation, library construction and, finally, sequencing were performed according the manufacturer's protocols. Bioinformatic data processing was performed on original BGI software - HALOS NIFTY-2.3.2.1011. The final report included risk assessment for trisomy $21,18,13$ and SCAs.

Women with high-risk of fetus chromosomal anomalies, evaluated by NIPT were recommended to undergo IPD by amniocentesis preferably or CVS following karyotyping and/or chromosomal microarray analysis (CMA).

The "true positive" was defined as those positive NIPT results that were confirmed by prenatal genetic testing. The "false positive" was defined as positive NIPT results that were shown to be euploid by follow-up invasive diagnostic genetic testing. 
Table 2. Performance of noninvasive prenatal testing (NIPT) in detecting trisomies 21, 18 and 13, SCAs and RATs or CNVs.

\begin{tabular}{|c|c|c|c|}
\hline & \multirow[b]{2}{*}{ Result } & \multicolumn{2}{|c|}{ Number of samples } \\
\hline & & $\begin{array}{l}\text { High-risk } \\
\text { group } \geq 1: 100\end{array}$ & $\begin{array}{l}\text { Intermediate-risk } \\
\text { group 1:101-1:2500 }\end{array}$ \\
\hline \multirow{4}{*}{ Trisomy 21} & Positive NIPT result & 38 & 12 \\
\hline & TP & 38 & 8 \\
\hline & FP & 0 & 1 \\
\hline & no data* & 0 & 3 \\
\hline \multirow{4}{*}{ Trisomy 18} & Positive NIPT result & 17 & 0 \\
\hline & TP & 17 & 0 \\
\hline & FP & 0 & 0 \\
\hline & no data* & 0 & 0 \\
\hline \multirow{4}{*}{ Trisomy 13} & Positive NIPT result & 2 & 3 \\
\hline & TP & 2 & 2 \\
\hline & FP & 0 & 1 \\
\hline & no data* & 0 & 0 \\
\hline \multirow{4}{*}{ SCAs } & Positive NIPT result & 3 & 19 \\
\hline & $\mathrm{TP}$ & 2 & 5 \\
\hline & FP & 0 & 9 \\
\hline & no data* & 1 & 5 \\
\hline \multirow{4}{*}{ RATs or CNVs } & Positive NIPT result & 4 & 19 \\
\hline & $\mathrm{TP}$ & 2 & 4 \\
\hline & $\mathrm{FP}$ & 2 & 11 \\
\hline & no data* & 0 & 4 \\
\hline
\end{tabular}

*The confirmation of the positive result is under the progress or patient denied an IPD procedure.

IPD, invasive prenatal diagnostics; SCA, sex chromosomal aneuploidy; RATs, rare autosomal trisomies; CNVs, copy number variations; TP, true positive; FP, false positive.

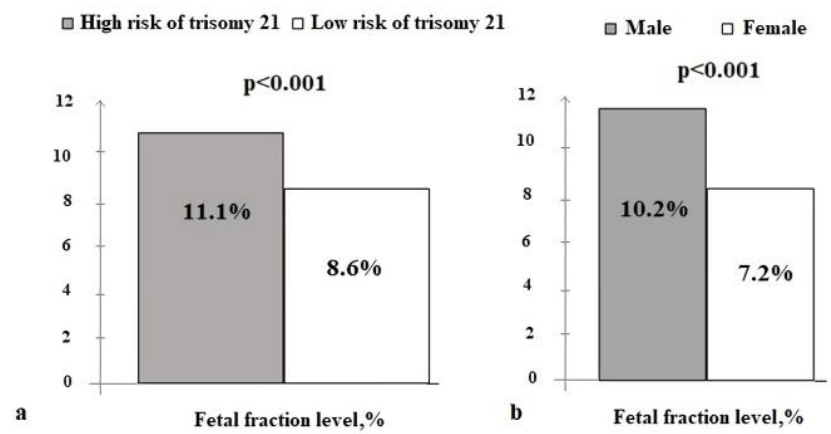

Figure 2. The average level of fetal fraction for patients depending on the NIPT results: risk of trisomy 21 (a) and fetal sex (b).

\section{Statistical analysis}

Descriptive data are presented in median and interquartile range for continuous variables and in percentage for categorical variables. Comparisons between groups were performed using the Mann-Whitney $U$ test for continuous variables and the chi-square $\left(X^{2}\right)$ test or Fisher's exact test for categorical variables, and $P$ values of $\leq 0.05$ were considered statistically significant.

\section{Results}

Between April and September 2020, total of 5,181 pregnant women blood samples were analyzed (Table 1). The average age of pregnant women was $34.4 \pm 4.3$ years. $53.0 \%$ of pregnant women were in the advanced maternal age ( 35 and older). The average gestation period was 14 weeks and 1 day \pm 1 week and 3 days. A total of $36.8 \%$ of pregnant women had a BMI below $25 \mathrm{~kg} / \mathrm{m}^{2}$ at the moment of testing. The majority of pregnancies were spontaneous and singleton (Table 1). All participants signed informed written consent before a blood collection.

After a prenatal double screen blood test there were 208 patients in a high-risk group, 4,973 patients in the intermediaterisk group and the rest of the patients were women in a low-risk group.

\section{NIPT results in high-risk pregnant women}

In the high-risk group $(\geq 1: 100) 64(30.8 \%)$ cases were confirmed by IPD after the positive NIPT results: 38 - trisomy 21 (Down syndrome), 17 - trisomy 18 (Edward syndrome), 2 trisomy 13 (Patau syndrome), two SCAs (one - Y-chromosome disomy (Jacobs syndrome) and one - X-chromosome dysomy with Y-chromosome monosomy (Klinefelter syndrome)). As well, two trisomies of chromosome 16 were detected during a whole genome sequencing. In one case the NIPT result was trisomy 18 and monosomy $X$ followed by IPD with 69, XXY result. Other 143 women were considered as negative (low-risk) by NIPT (Table 2 ).

\section{NIPT results in intermediate-risk pregnant women}

In the intermediate risk group (1:101 - 1:2500) (4973 samples), 53 (1.1\%) samples were considered as positive: 12 trisomy 21, three - trisomy 13, in 19 cases SCAs were found, in 19 - RAT (rare autosomal trisomy) or CNVs. The positive NIPT results of 19 cases were confirmed by IPD - trisomy 21 in 8 cases, trisomy 13 in 2 cases, SCA in 5 cases (X-chromosome monosomy in 2 cases, $\mathrm{X}$-chromosome disomy with $\mathrm{Y}$-chromosome monosomy in 1 case, $\mathrm{X}$-chromosome monosomy with $\mathrm{Y}$-chromosome disomy in 1 case and trisomy $X$-chromosome in 1 case) and 4 cases of rare chromosomal anomalies (described below). In 1 case of trisomy 21, 1 case of trisomy 13, 9 cases of SCA and 11 cases of RAT, chromosomal pathology was not confirmed by IPD. Twelve patients refused an IPD procedure. In 170 cases, NIPT was inconsistent due to low fetal fractions.

\section{Rare cases}

Twenty-one cases were considered positive for RATs or CNVs by NIPT (three cases in the high-risk group and 18 cases in the intermediate-risk group). Fourteen women proceeded with IPD, and chromosomal pathology was confirmed only in three cases. These chromosomal anomalies are rare and are not detectable by widely used NIPT techniques, which can detect only common chromosomal trisomies.

Case 1. Pregnant 29-year-old woman with a 1:137 risk of trisomy 21 according the results of the double screen blood test. NIPT result was also positive: increased risk of duplication of the short arm of a chromosome 2 was found. Amniocentesis was performed followed by a CMA. A microdeletion and a microduplication of the short arm of the chromosome 2 were detected, which were identified as pathogenic, associated with developmental delay and a specific phenotype.

Case 2. Pregnant 26-year-old woman, with a 1:2248 risk of trisomy 21 according to the results of the double screen blood test. NIPT results revealed a high risk of trisomy 7 . Amniocentesis was performed on the 18th gestation week. Karyotyping revealed a true trisomy 7 mosaicism ( $12 \%$ trisomy 7 cells in amniocyte cultures). The mosaic form of trisomy 7 is a rare chromosomal abnormality with a highly variable phenotype [14]. 
Case 3. Pregnant 35-year-old woman with a 1:948 risk of trisomy 21 according to the results of the double screen blood test. NIPT revealed a high risk of duplication of the short arm of the chromosome 12. After the genetic consulting an IPD was recommended, and an amniocentesis was performed on the 17-18 gestation week. Fetal karyotype was $47, \mathrm{XX},+$ mar. The marker chromosome was made up of two mirror copies of the short arm of the chromosome 12. In the Rarechromo database of rare genetic diseases, the pathology is described as a tetrasomy of the short arm of chromosome 12 (Pallister-Killian syndrome). Pathology is characterized by facial dysmorphia, defects of the cardiovascular system and others [15].

All in all, the rate of FP results for NIPT was $0.35 \%$.

Out of 5194 samples, $3.4 \%$ of cases (176 samples) blood retesting was recommended due to a low fetal fraction (FF) (below 3.5\%).

Analyzing samples with low FF $(<3.5 \%)$, significantly higher weight and body mass index (BMI) of women were observed in comparison with normal FF samples: $70.5 \mathrm{~kg}[60,83]$ for low FF and $65 \mathrm{~kg}$ [58;74] for normal, $(p<0.001), \mathrm{BMI}-25.7 \mathrm{~kg} / \mathrm{m}^{2}$ [22.2;30.8] for lower FF and $23.4 \mathrm{~kg} / \mathrm{m}^{2}$ [20.9;26.8] for normal, $\mathrm{p}<0.001$

Analyzing samples depending on FF, it was shown, that positive for trisomy 21 NIPT results were associated with a higher $\mathrm{FF}$, than samples with negative results: $11.1(7.8,14.2) \%$ and 8.6 $(6.3,11.4) \%, p<0.001$. The cut point for significant difference was $10 \%$ FF $(p<0.001)$. The same tendency was not revealed for trisomy 18 and 13 probably due to a small number of trisomy 18 and 13 samples. It was also shown, that fetal fraction is significantly higher with male fetus, than female: $10.2(7.6,13.4) \%$ and $7.2(5.3,9.2) \%, p<0.001$ (Figure 2).

We did not find any significant difference between the age of women with positive and negative NIPT results for trisomy 21 $(p=0.457)$. But summarizing all the positive NIPT results for all anomalies showed, that these were significantly higher in women at the age of 39 and older: $6.9 \%$ of positive results in women older than 39 and $5 \%$ for women under 39 -year-old, $p=0.009$.

There was no significant difference in frequency of positive NIPT results in spontaneous and in vitro fertilization pregnancies $(p=0.728)$

\section{Discussion \\ World experience}

The detection of cfDNA in maternal plasma in 1997, launched a new era of non-invasive prenatal testing [20]. Since then, lots of investigations made that in 2010 lead to first NIPT introduction in China [21]. As soon as in 2011 it was applied for clinical use in Hong Kong and the United States [22-24]. Ever since, the test has been distributed fast and has become increasingly available to pregnant women worldwide, either in a commercial or in a stateregulated setting [25].

Worldwide there are two common scenarios of NIPT-based prenatal screening - NIPT as a second line test after first trimester screening results in risk groups using current risk cut-offs; and NIPT as a first-line test in all pregnant women instead or together with first trimester screening $[26,27]$. Most of the countries who adopted NIPT in governmental prenatal screening programs are using it as a second line test due to high expenses. That adoption scenario results in lower rate of false positive results and lower rate of invasive procedures. If NIPT as a second line test covers not only high-risk groups, but groups with lower risk as well, it also helps to increase the detection rate of common aneuploidies. This scenario has also been chosen in Moscow.

In some European countries as Netherland and Belgium NIPT is provided to women as a first-line test on governmental program $[4,5]$. These countries made lots of investigation and found that NIPT adoption as first-line test is not only clinically, but economically effective as well. It was declared, that NIPT improves the overall detection rate from 81 to $99 \%$, reduces the number of invasive procedures by $72 \%$ in high-risk group and by $60 \%$ in all pregnant women groups, and also that NIPT declines the number of missed cases from 77 to $5[28,29]$.

In Russia first step of NIPT adoption was made in April 2020, when it was integrated in actual prenatal screening as second-line test. Though only 6-month results are available, effectiveness of the project was already observed: in addition to first trimester screening results 8 cases of common aneuploidies, 6 SCAs and 3 CNVs were detected by NIPT. As for potential effect - among 208 women considered as high-risk by first trimester screening results, only 50 were confirmed as high-risk by NIPT. Though it lowers false positive rate to $0.04 \%$ (for common aneuploidies), this kind of effectiveness is now only potential as prenatal screening regulation in Russia doesn't take into account NIPT results and all women with high risk after first trimester screening have to undergo invasive procedures.

\section{NIPT false positives and false negatives}

All in all, false positive rate for all anomalies in our study was as much as $0.3 \%$ : $0.04 \%$ for common aneuploidies, $0.11 \%$ for SCA and $0.19 \%$ for CNVs. This rate much lower than in previous studies [30]. Though we have to take into account that these are only 6 month results. Identification of pathogenic CNVs was associated with lower positive predictive values and higher false-positive rates, likely because of the low prevalence of the individual targeted microdeletion and microduplication syndromes in the general population. True positive and false negative for RATs and CNVs rates are comparable with other studies. The major factors contributing to false-positive cfDNA results probably were maternal copy number variants and fetal/placental mosaicism [31].

False negative results are really rare for NIPT and is as much as $0.08 \%$ [2]. We didn't have any in our study.

\section{Fetal fraction and NIPT results}

The accuracy of NIPT is affected by multiple technical and biological factors that are all integrated with and affected by each other. These include the number of sequencing tags, FF, GC base content, and other. Because cfDNA is a mixture of genomic DNA fragments of maternal and fetal (placental) origin [32], the NIPT accuracy is directly related to the FF [33]. In our study $3.4 \%$ of cases had low FF, that was a reason for retesting. Up to date in different studies it was shown, that numerous maternal and fetal characteristics have been associated with reductions in FF including early gestation age, maternal obesity, and multiple pregnancies, low level of hCG $\beta$ and type of conception [34, 35]. In our study we analyzed all of these parameters except for hCG $\beta$ data, that was not available. We haven't observed any reliable 
differences between the level of FF and maternal age, type of conception and type of pregnancies.

But statistically significant dependance of the concentration of $\mathrm{FF}$ and both $\mathrm{BMI}$ and weight of the patients was shown. Along with weight and BMI rising, FF was declining.

Maternal BMI is the most significant demographic variable that affects FF [36]. In the study of Ashoor G. et al. it was shown progressive declining of median $\mathrm{FF}$ in obese women: in $60 \mathrm{~kg}$ women it was $11.7 \%$ in and $3.9 \%$ in women who weighed $160 \mathrm{~kg}$. Remodeling of adipose tissue in obese pregnant women is associated with a 2 -fold increase in a marker of total DNA - GAPDH (glyceraldehyde-3-phosphate dehydrogenase) in serum. The fetal DNA is unaffected, but the increased maternal DNA results in an overall lower FF. Together, maternal weight and fetal gestational age accounted for as much as $27 \%$ of the interindividual variation seen in FF [37].

In our study it was also shown, that higher FF was more common for male fetus and for fetuses with high risk of trisomy 21. The same was also published in some other studies, showing that euploid male fetus pregnancies with high risk of trisomies 21 had higher FF [38]. For trisomies 18, 13 and monosomy $X$, vice versa the study has shown lower FF. Higher FF in fetuses with trisomy 21 may be one of reason that test performance for trisomy 21 is better than for trisomies 18 and 13. In our study the cut-off for high trisomy 21 risk was $10 \%$ FF. We didn't observe any significant difference in $\mathrm{FF}$ for trisomies 13,18 and monosomy $\mathrm{X}$, that is probably due to low incidence yet.

\section{Maternal age and NIPT results}

As advanced maternal age ( $\geq 35$ years) is reported to be associated with various pregnancy complications including genetic abnormalities in children, in our study we also analyzed these connections. Though in most of the published studies the cut-off age was 35 , we observed significantly higher risk of chromosomal anomalies in women at the age of 39 and older. A number of studies have reported that fetal chromosomal abnormalities showing a close association with maternal age included trisomy 21 , trisomy 18 , trisomy 13 , triple $\mathrm{X}$ syndrome, and $\mathrm{XYY}$ syndrome $[39,40]$.

Since not only common aneuploidies are the case, but also pathogenic sub-chromosomal deletions and duplications occurring de-novo. Risk for microdeletions and microduplications is the same for all pregnancies regardless of the maternal age. Taking that into account in august 2020 ACOG proposed prenatal screening for aneuploidy for all pregnant women, regardless of age or other risk factors [41].

\section{Advantages and disadvantages of NIPT}

Along with its clinical benefits NIPT has lots of social and economic benefits as well. Since NIPT is an expensive technique, its economic benefit can be identified in a delayed period. NIPT can reduce both direct and indirect costs of prenatal diagnostics and maintenance of disabled people. The decrease in direct costs is due to a potential decrease in the number of IPDs, as well as a decrease in budget payments for the maintenance of disabled people. The average life expectancy of a person with Down syndrome is 60 years. Thus, NIPT allows to reduce the annual governmental costs during the 60 years.
The social benefits are related to both sampling procedure, and to NIPT methodology. NIPT is as safe as simple blood testing and doesn't require any surgical intervention. The simplicity and safety of NIPT can lower the level of anxiety, that is quite important in pregnant women with hormone-driven emotional instability. Low frequency of false positive and false negative results determines the high confidence of pregnant women in NIPT results, that was shown in different publications [42]. In our study we are also assessing women's attitude to NIPT - analysis is in progress.

NIPT is available from 9th gestation week and up to delivery, while the current first trimester prenatal screening is limited to 1114 weeks. This allows women to be provided with information about fetus chromosomal anomalies risk up to 22 weeks gestation - the deadline for medical termination of a pregnancy in Russia. If woman is using NIPT only to obtain information about the health of the fetus, without intention to terminate the pregnancy, period of NIPT performance is limited only by delivery. A longer period for NIPT performance leads to more pregnant women covered with prenatal screening.

Of course, the main advantage of NIPT is its high sensitivity and specificity for common aneuploidies - NIPT has the highest accuracy among all screening methods for detecting Down syndrome (up to 99\%), as well as high accuracy for detecting other frequent anomalies (Edwards syndrome, Patau syndrome). In addition to the most common pathologies, that are also assessed by first trimester prenatal screening, NIPT allows to evaluate the risks of other chromosomal abnormalities, including microchromosomal arrangements, which can be omitted during standard routine prenatal screening.

In spite of the obvious advantages of NIPT adoption, there is always another side of the coin. Adoption of NIPT in many countries led to a decrease in IPD procedures, that has negative consequences as some authors proposed. It was suggested that declining of IPD amount causes declining of practice skills of physician leading to significantly higher miscarriage rates [43]

\section{Conclusion}

Adoption of NIPT as second-line test in Moscow has already shown its effectiveness, despite there being only six months of available results. The major advantage of using cfDNA testing was the reduction in rates of false positive results. Our findings, however, suggest that cfDNA testing merits serious consideration as a primary screening method for fetal autosomal aneuploidy. The NIPT should be recommended for all pregnant women both in a high-risk group and intermediate-risk group. More widespread use of NIPT is needed and if economically possible - as a first-line test.

\section{Conflicts of interest}

The authors have no conflicts of interest relevant to this article.

Funding

The study was funded by Moscow Health Department (№ 01-04-410, 06.02.2020.)

\section{References}

1. Baranov AA, Namazova-Baranova LS, Albitskiy VYu, Terletskaya RN Tendencies of infantile and child mortality in the conditions of 
implementation of the modern strategy of development of health care of the Russian Federation. Annals of the Russian Academy of Medical Sciences 2017; 72(5): 375-382. Russian. https://doi.org/10.15690/vramn867.

2. Bianchi DW, Wilkins-Haug L. Integration of noninvasive DNA testing for aneuploidy into prenatal care: what has happened since the rubber met the road? Clin Chem 2014; 60(1): 78-87. https://doi.org/10.1373/clinchem.2013.202663.

3. van Schendel RV, van El CG, Pajkrt E, Henneman L, Cornel MC. Implementing non-invasive prenatal testing for aneuploidy in a national healthcare system: global challenges and national solutions. BMC Health Serv Res 2017; 17(1): 670. https://doi.org/10.1186/s12913-017-2618-0.

4. van der Meij KRM, Sistermans EA, Macville MVE, Stevens SJC, Bax CJ, Bekker MN, et al. TRIDENT-2: National Implementation of Genomewide Non-invasive Prenatal Testing as a First-Tier Screening Test in the Netherlands. Am J Hum Genet 2019; 105(6): 1091-1101. https://doi.org/10.1016/j.ajhg.2019.10.005.

5. Neyt M, Hulstaert F, Gyselaers W. Introducing the non-invasive prenatal test for trisomy 21 in Belgium: a cost-consequences analysis. BMJ Open 2014; 7; 4(11): e005922. https://doi.org/10.1136/bmjopen2014-005922.

6. Porreco RP, Garite TJ, Maurel K, Marusiak B, Ehrich M, van den Boom $D$, et al. Noninvasive prenatal screening for fetal trisomies $21,18,13$ and the common sex chromosome aneuploidies from maternal blood using massively parallel genomic sequencing of DNA. Am J Obstet Gynecol 2014; 211(4): $365 . \quad$ e1-12. https://doi.org/10.1016/j.ajog.2014.03.042.

7. Gregg AR, Skotko BG, Benkendorf JL, Monaghan KG, Bajaj K, Best RG, et al. Noninvasive prenatal screening for fetal aneuploidy, 2016 update: a position statement of the American College of Medical Genetics and Genomics. Genet Med 2016; 18(10): 1056-1065. https://doi.org/10.1038/gim.2016.97.

8. Suciu ID, Toader OD, Galeva S, Pop L. Non-invasive prenatal testing beyond trisomies. J Med Life 2019; 12(3): 221-224. https://doi.org/10.25122/jml-2019-0053.

9. Shaw SW, Chen CP, Cheng PJ. From Down syndrome screening to noninvasive prenatal testing: 20 years' experience in Taiwan. Taiwan J Obstet Gynecol 2013; 52(4): 470-474. https://doi.org/10.1016/j.tjog.2013.10.003.

10. Bianchi DW, Chudova D, Sehnert AJ, Bhatt S, Murray K, Prosen TL, et al. Noninvasive prenatal testing and incidental detection of occult maternal malignancies. JAMA 2015; 314(2): 162-169. https://doi.org/10.1001/jama.2015.7120.

11. Mackie FL, Hemming K, Allen S, Morris RK, Kilby MD. The accuracy of cell-free fetal DNA based non-invasive prenatal testing in singleton pregnancies: a systematic review and bivariate meta-analysis. BJOG 2017; 124(1): 32-46. https://doi.org/10.1111/1471-0528.14050.

12. Order of the Ministry of Health of Russia dated 01.11.2012 N 572n (revised from 21.02.2020) "On approval of the Procedure for the provision of medical care in the field of obstetrics and gynecology (except for the use of assisted reproductive technologies)". http://www.consultant.ru/document/cons doc LAW 144927/

13. Order of the Moscow Department of Health of 13.03.2020 N 199 "On the organization of a non-invasive prenatal test in the city of Moscow". https://www.mos.ru/dzdrav/documents/departmentacts/view/237308220/

14. Chen CP, Hung FY, Chern SR, Chen SW, Wu FT, Town DD, et al. Prenatal diagnosis of mosaicism for trisomy 7 in a single colony at amniocentesis in a pregnancy with a favorable outcome. Taiwan J Obstet Gynecol 2019; 58(6): 852-854.

15. Pallister-Killian syndrome. Rare Chromosome Disorder Support Group, 2016; https://www.rarechromo.org/media/information/Chromosome\%2012 /Pallister-Killian\%20syndrome\%20FTNW.pdf
16. Health Quality Ontario. Noninvasive Prenatal Testing for Trisomies 21 18, and 13, Sex Chromosome Aneuploidies, and Microdeletions: A Health Technology Assessment. Ont Health Technol Assess Ser 2019; 19(4): 1-166. https://pubmed.ncbi.nlm.nih.gov/30847010/

17. Samango-Sprouse C, Kırkızlar E, Hall MP, Lawson P, Demko Z, Zneimer $\mathrm{SM}$, et al. Incidence of $X$ and $Y$ chromosomal aneuploidy in a large child bearing population. PLoS One 2016; 11(8): e0161045. https://doi.org/10.1371/journal.pone.0161045.

18. Benn PF, Malvestiti B, Grimi F, Maggi G, Simoni F, Grati R. Rare autosomal trisomies: comparison of detection through cell-free DNA analysis and direct chromosome preparation of chorionic villus samples. Ultrasound Obstet Gynecol 2019; 54 (4): 458-467. https://doi.org/10.1002/uog.20383.

19. Liu H, Gao Y, Hu Z, Lin L, Yin X, Wang J, et al. Performance evaluation of NIPT in detection of chromosomal copy number variants using lowcoverage whole-genome sequencing of plasma DNA. PLoS One 2016; 11(7): e0159233. https://doi.org/10.1371/journal.pone.0159233

20. Lo YM, Corbetta N, Chamberlain PF, Rai V, Sargent IL, Redman CW, et al. Presence of fetal DNA in maternal plasma and serum. Lancet 1997; 350(9076), 485-487. https://doi.org/10.1016/s0140-6736(97)02174-0.

21. Tian $C$, Deng $T$, Zhu $X$. Gong $C$, Zhao $Y$, Wei $Y$, et al. Evidence of compliance with and effectiveness of guidelines for noninvasive prenatal testing in China: a retrospective study of 189,809 cases. Sci China Life Sci 2020; 63 (3), 319-328. https://doi.org/10.1007/s11427019-9600-0.

22. Lau TK, Chan MK, Lo PS, Chan HY, Chan WK, Koo TY, et al. Clinical utility of noninvasive fetal trisomy (NIFTY) test - early experience. J Matern Fetal Neonatal Med 2012; 25(10): 1856-1859. https://doi.org/10.3109/14767058.2012.678442.

23. Agarwal A, Sayres LC, Cho MK, Cook-Deegan R, Chandrasekharan S. Commercial landscape of noninvasive prenatal testing in the United States. Prenat Diagn 2013; 33(6): 521-531. https://doi.org/10.1002/pd.4101.

24. Chandrasekharan S, Minear MA, Hung A, Allyse M. Noninvasive prenatal testing goes global. Sci Transl Med 2014; 6(231): $231 \mathrm{fs} 15$ https://doi.org/10.1126/scitranslmed.3008704

25. Bianchi DW, Chiu RWK. Sequencing of circulating cell-free DNA during pregnancy. N Engl J Med 2018; 379(5), 464-473. https://doi.org/10.1056/neimra1705345.

26. Noninvasive prenatal testing for fetal aneuploidy. Available from: http://www.acog.org/Resources-And-Publications/CommitteeOpinions/Committee-on-Genetics/Noninvasive-Prenatal-Testing-forFetal-Aneuploidy. Accessed July 28, 2014

27. Gregg AR, Gross SJ, Best RG, Monaghan G, Bajaj K, Skotko BG, et al. ACMG statement on noninvasive prenatal screening for fetal aneuploidy. Genet Med 2013; 15(5): 395-398. https://doi.org/10.1038/gim.2013.29.

28. Oepkes D, Page-Christiaens GC, Bax CJ, Bekker MN, Bilardo CM, Boon $E M$, et al. Trial by Dutch laboratories for evaluation of non-invasive prenatal testing. Part I-clinical impact. Prenat Diagn 2016; 36(12): 1083-1090. https://doi.org/10.1002/pd.4945

29. Kostenko E, Chantraine F, Vandeweyer K, Schmid M, Lefevre A, Hertz $D$, et al. Clinical and economic impact of adopting noninvasive prenatal testing as a primary screening method for fetal aneuploidies in the general pregnancy population. Fetal Diagn Ther 2019; 45(6): 413-423. https://doi.org/10.1159/000491750.

30. Wang $Y$, Li S, Wang W, Dong $Y$, Zhang $M$, Wang $X$, et al. Cell-free DNA screening for sex chromosome aneuploidies by non-invasive prenatal testing in maternal plasma. Mol Cytogenet 2020; 13: 10. https://doi.org/10.1186/s13039-020-0478-5.

31. Samura O, Okamoto A. Causes of aberrant non-invasive prenatal testing for aneuploidy: A systematic review. Taiwan J Obstet Gynecol 2020; 59(1): 16-20. https://doi.org/10.1016/j.tjog.2019.11.003.

32. Palomaki GE, Kloza EM. Prenatal cell-free DNA screening test failures: a systematic review of failure rates, risks of Down syndrome, and 
impact of repeat testing. Genet Med 2018; 20(11): 1312-1323. https://doi.org/10.1038/gim.2018.22.

33. Kinnings SL, Geis JA, Almasri E, Wang H, Guan X, McCullough RM, et al. Factors affecting levels of circulating cell-free fetal DNA in maternal plasma and their implications for noninvasive prenatal testing. Prenat Diagn 2015; 35(8): 816-822. doi: 10.1002/pd.4625. https://doi.org/10.1002/pd.4625.

34. Zhang $H$, Gao $Y$, Jiang $F$, Fu $M$, Yuan $Y$, Guo $Y$, et al. Noninvasive prenatal testing for trisomies 21, 18 and 13: clinical experience from 146,958 pregnancies. Ultrasound Obstet Gynecol 2015; 45(5): 530-538. https://doi.org/10.1002/uog.14792.

35. Livergood MC, LeChien KA, Trudell AS. Obesity and cell-free DNA "no calls": is there an optimal gestational age at time of sampling? Am J Obstet Gynecol 2017; 216(4):413.e1-413.e9. https://doi.org/10.1016/j.ajog.2017.01.011.

36. Ashoor G, Poon L, Syngelaki A, Mosimann B, Nicolaides KH. Fetal fraction in maternal plasma cell-free DNA at 11-13 weeks' gestation: effect of maternal and fetal factors. Fetal Diagn Ther 2012; 31: 237 243. https://doi.org/10.1159/000337373.

37. Badeau M, Lindsay $C$, Blais J, Nshimyumukiza L, Takwoingi $Y$, Langlois $S$, et al. Genomics-based non-invasive prenatal testing for detection of fetal chromosomal aneuploidy in pregnant women. Cochrane Database Syst Rev 2017; 11(11): CD011767. https://doi.org/10.1002/14651858.cd011767.pub2.

38. Wang E, Batey A, Struble C, Musci T, Song K, Oliphant A. Gestational age and maternal weight effects on fetal cell-free DNA in maternal plasma. Prenat Diagn 2013; 33(7): 662-666. https://doi.org/10.1002/pd.4119.

39. Poon LC. First trimester prediction of preeclampsia by ultrasound. Ultrasound Med Biol 2017; 43(Supplement 1): S134.

40. Pös O, Budiš J, Szemes T. Recent trends in prenatal genetic screening and testing. F1000Res 2019; 8: F1000 Faculty Rev-764. https://doi.org/10.12688/f1000research.16837.1.

41. American College of Obstetricians and Gynecologists' Committee on Practice Bulletins - Obstetrics; Committee on Genetics; Society for Maternal-Fetal Medicine. Screening for Fetal Chromosomal Abnormalities: ACOG Practice Bulletin, Number 226. Obstet Gynecol 2020; 136(4): e48-e69. https://doi.org/10.1097/aog.0000000000004084.

42. Beaudet AL. Using fetal cells for prenatal diagnosis: History and recent progress. Am J Med Genet C Semin Med Genet 2016; 172(2): 123-7. https://doi.org/10.1002/ajmg.c.31487.

43. Hui L, Tabor A, Walker SP, Kilby MD. How to safeguard competency and training in invasive prenatal diagnosis: 'the elephant in the room'. Ultrasound Obstet Gynecol 2016; 47(1): 8-13. https://doi.org/10.1002/uog.15806.

\section{Authors:}

Anton S. Olenev - MD, PhD. Head of the branch of Moscow City Health Department „City Clinical Hospital №24” - „Perinatal center”, Moscow, Russia. https://orcid.org/0000-0001-9632-6731.

Elena E. Baranova - MD, PhD, medical geneticist. Medical Director of Evogen LLC. Assistant professor Russian Medical Academy of Continuous Professional Education Department of medical genetics., Moscow, Russia. https://orcid.org/0000-0001-9638-2303.

Olesya V. Sagaydak - MD, PhD. Deputy Head of Medical Department of Evogen LLC, Moscow, Russia. https://orcid.org/0000-0002-2534-8463.

Alexandra M. Galaktionova - MD, PhD, medical geneticist, obstetriciangynecologist, expert in prenatal diagnostics at Evogen LLC, Moscow, Russia. https://orcid.org/0000-0001-8602-5441.

Ekaterina S. Kuznetsova - PhD, clinical sequence expert of Evogen LLC, Moscow, Russia. https://orcid.org/0000-0003-3316-3183.

Madina T. Kaplanova - MD, medical geneticist of Evogen LLC, Moscow, Russia. https://orcid.org/0000-0001-6715-706X.

Maxim S. Belenikin - PhD. Deputy General Director for science of Evogen LLC, Moscow, Russia. https://orcid.org/0000-0002-6556-163X.
Ekaterina N. Songolova - MD, PhD, the highest qualification category. Deputy chief physician for obstetric and gynecological care, L.A. Vorokhobov City Clinical Hospital №67, Moscow, Russia. https://orcid.org/0000-0003-4366-2306. 